\title{
Antibodies to Plasmodium falciparum sporozoites following a malarial outbreak in a non-endemic area of Sri Lanka
}

\author{
M. de S. Wijesundera ${ }^{1}$, J. S. M. Peiris ${ }^{2}$, Y. G. Ariyaratne ${ }^{2}$, Antonio S. Verdini ${ }^{3}$, Antonello Pessi ${ }^{3}$ and \\ Giuseppe Del Giudice ${ }^{4}{ }^{1}$ Department of Parasitology and ${ }^{2}$ Department of Microbiology, Faculty of Medicine, \\ University of Peradeniya, Sri Lanka; ${ }^{3}$ Polypeptide Synthesis Department, Eniricerche, Monterotondo, Italy; \\ ${ }^{4}$ WHO Immunology Research and Training Centre, Department of Pathology, University of Geneva, Switzerland
}

\begin{abstract}
An enzyme-linked immunosorbent assay (ELISA) based on the synthetic peptide (NANP) 40 was used to characterize the sporozoite antibodies in an unusual Plasmodium falciparum outbreak in a non-malarious area in Sri Lanka. A positive antibody response was seen in $62 \%$ of patients with their first $P$. falciparum illness. There was no correlation between sporozoite antibodies and the antibody against blood stages, determined by immunofluorescence assay. The majority $(91 \%)$ of the patients lost the antibodies to circumsporozoite (CS) protein within one year (in the absence of re-exposure). Three patients had high levels of CS antibodies even after one year, and this persistence was related to the level of the initial antibody response. In the area of the outbreak $10 \%$ of schoolchildren had antibodies to the (NANP) 40 peptide. $21 \%$ of the 42 children with present or past overt malaria were antibody positive. Of the children with no such background, $8 \%$ were antibody positive. The corresponding seropositivity rates for asexual blood stages were $31 \%$ and $1 \%$ for the 2 groups respectively. It is concluded that (NANP) ${ }_{40}$ ELISA is potentially a valuable tool in sero-epidemiology, particularly in situations of seasonal transmission and recurrences due to drug resistance.
\end{abstract}

\section{Introduction}

An antibody response to the sporozoite stages of malaria parasites were first described by VANDENBERG et al. (1969) using the circumsporozoite precipitation test. However, it was only with the introduction of an immunofluorescence (IFA) test for the detection of antibodies to sporozoites that a human antibody response to these stages of the Plasmodium falciparum parasite was documented by NARDIN $e t$ al. (1979). There workers showed that in an area with hyperendemic malaria, The Gambia, sporozoite antibodies were widely prevalent in humans, and that seropositivity increased with age. Similar observations were reported for human $P$. vivax infections in Thailand (TAPCHAISRI et al, , 1983). However, due to the scarcity of antigen used for both these techniques, they were of limited applicability in epidemiological studies. The cloning of the circumsporozoite (CS) protein antigen of $P$. falciparum and the elucidation of its structure (DAME et al., 1984; ENEA et al., 1984; NUSSENZWEIG \& NUSSENZWEIG, 1985) paved the way for the use of recombinant (HOFFMAN et al., 1986) and synthetic antigens (ZAVALA et al., 1986; CAMP-

Author for correspondence: $M$. de S. Wijesundera, Department of Parasitology, Faculty of Medicine, Peradeniya, Sri Lanka.
BELL et al., 1987; DEL GIUDICE et al., 1987a) in immunoassays. Studies on the immune responses to the CS protein antigen in $P$. falciparum have been carried out using these techniques, and have confirmed the data obtained using the IFA test. However, many questions remain to be answered.

As most of the studies on the CS antibody response reported to date have been carried out in areas of hyper- or holoendemic malaria, there are limited data on the response to exposure to a single infection and the duration of the response.

An unusual outbreak of $P$. falciparum malaria in a village in a normally non-malarious area of Sri Lanka offered us an opportunity to investigate some of these questions. The outbreak was associated with the recent completion of a dam upstream of the village and the formation of pools of water in the river bed during the severe drought experienced in 1987 (WIJESUNDERA, 1988). The village had not experienced malaria before, and thus provided a 'virgin' population with respect to $P$. falciparum. This contention was further supported by the fact that in the recent past (until 1984) malaria in Sri Lanka has predominantly $(95 \%)$ been due to $P$. vivax. This report documents the antibody response of these villagers to the (NANP) 40 synthetic antigen (DEL GIUDICE et al., 1987b).

\section{Materials and Methods}

Venous blood samples from 101 patients with parasitologically confirmed $P$. falciparum malaria were obtained after informed consent. The patients were residents of a village (Waratenne, elevation $500 \mathrm{~m}$ ) in a hitherto non-malarious area of the island. This village, which had a population of 458 in 75 households, was subjected to an outbreak of $P$. falciparum malaria during January-June 1987 (WIJESUNDERA, 1988); there has been no significant malaria in this area before or since then. The patients studied were those who attended a voluntary treatment health centre during May-June 1987. During this period, of the 184 confirmed malaria patients treated at the clinic, 106 were from this village (an attack rate of $23 \%$ ). Chloroquine or amodiaquine was used for treatment of the acute attack, but all the patients suffered one or more recrudescences of illness, in spite of therapy (evidence of RI resistance). At the time of blood collection, $90 \%$ of patients had received 2 or more, and $63 \% 3$ or more, courses of drugs within a 2-3 month period. The outbreak was contained using sulfadoxine/pyrimethamine (Fansidar $^{(B)}$.

A second blood sample was collected one year later from 55 of these patients, together with information 
of febrile episodes and travel to malarious areas during the intervening year.

Sera from 234 apparently healthy schoolchildren in 2 schools in this area were also collected in June the same year, after obtaining parental consent.

Sera from 115 schoolchildren from an area where malaria was not active (Hatton; elevation $1270 \mathrm{~m}$ ) were collected as controls.

Detection of antibodies to $\mathrm{P}$. falciparum sporozoites by

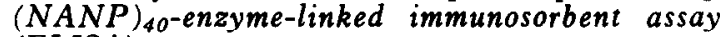
(ELISA)

The (NANP) ${ }_{40}$-ELISA was carried out as described previously (DEL GIUDICE et al., 1987a). ELISA plates were precoated with (NANP) 40 antigen (test antigen) or phosphate-buffered saline (control antigen) at the World Health Organization Immunology Research and Training Centre in Geneva, transported to Sri Lanka, and stored at $4^{\circ} \mathrm{C}$ until used within 12 weeks of coating. These precoated plates have been shown to be stable for at least 6 months at $4^{\circ} \mathrm{C}, 25^{\circ} \mathrm{C}$ (room temperature) and $37^{\circ} \mathrm{C}$ (Del Giudice, unpublished data). An anti-human immunoglobulin (Ig) G/M/A kappa/lambda conjugate (Dako, Denmark) was used at a dilution of 1 in 400 , the optimal dilution as assessed by chess board titrations. The optical density (OD) was read on an ELISA reader (Dynatech Minireader) at $495 \mathrm{~nm}$. Serum specimens were screened at a dilution of 1 in 200 in duplicate wells, on plates with test antigen and control antigen respectively. The difference of OD between the test antigen and control antigen for a given serum was taken as the indicator of specific reaction and is the quantity used in all analysis of data below. A negative and a positive control serum were included in each day's experiment.
Detection of antibodies against asexual blood stages of $\mathrm{P}$. falciparum by indirect fluorescent assay (IFA)

IFA was carried out according to standard methods using cultured $P$. falciparum. Thin film antigen slides air-dried and acetone-fixed (provided by Dr Allan Saul of the Queensland Institute of Medical Research, Australia) and fluorescein isothiocyanate-conjugated goat anti-human IgG (Nordic, Netherlands) at a working dilution of 1 in 50 in $0.05 \%$ Evans blue in PBS (pH 7.2) were used.

\section{Results}

Circumsporozoite antibody response in the control population

The CS antibody results for the 115 control sera are shown in Fig. 1, C. The mean OD difference was 0.027 (standard deviation $(\mathrm{SD})=0.09$ ). The cut-off value in the test was computed as 0.2 (mean $+2 \mathrm{SD}$ ) for a $95 \%$ level of confidence and 0.3 (mean +3 SD) for a $99 \%$ level of confidence. Five of these children (4\%) were positive at an OD difference $\geqslant 0.2$, and 2 (2\%) were positive at an OD difference $\geqslant 0.3$.

\section{Circumsporozoite antibody levels in schoolchildren in the} area of the outbreak

The CS antibody results for these children are shown in Fig. 1, B. Twenty-four of $234(10 \%)$ of the children showed an OD difference $\geqslant 0.2$ and $17(7 \%)$ a difference $\geqslant 0 \cdot 3$. Fifteen of $234(6 \%)$ sera tested by IFA for asexual stage antibodies were positive at a cut-off titre of $1 / 32$. Only 4 of the sera were positive by both tests. On the basis of clinical history (febrile episodes), palpable spleen, and blood film positivity ( 5 children), 42 children were classified as having, or having had, infection during the outbreak ('malaria'

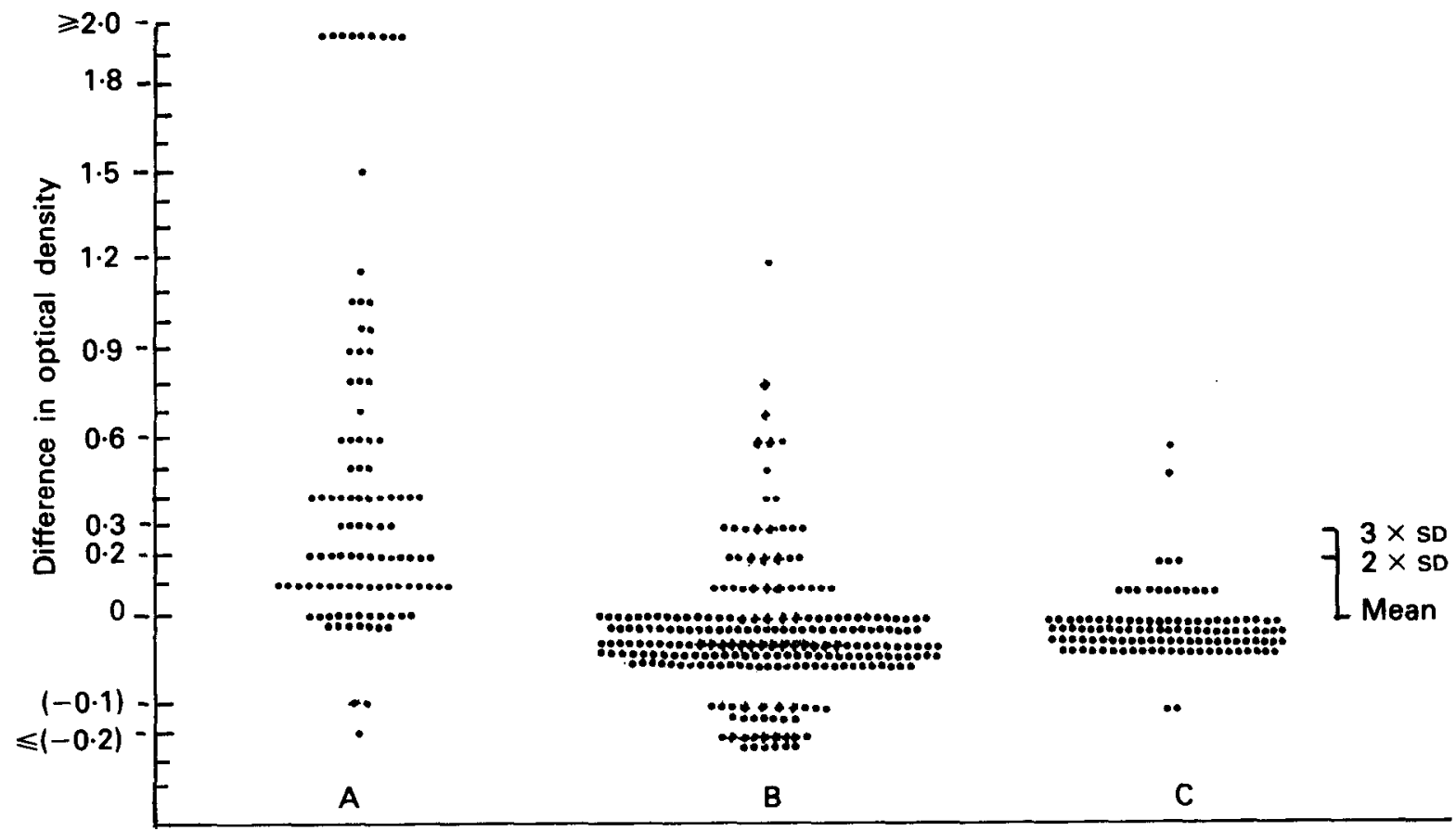

Fig. 1. The (NANP) 40 enzyme-linked immunosorbent assay results of (A) patients with acute malaria, (B) schoolchildren in the malaria outbreak area, and (C) schoolchildren in a non-malarious area. The mean plus 2 and 3 standard deviations of the control group (c) are shown. 
group). Nine of $42(21 \%)$ of them were positive for CS antibody, compared to 15 of $192(8 \%)$ positive in the remaining children with no such history. In contrast, $31 \%$ of the 'malaria' group were IFA positive, while only $1 \%$ of those with no history of malaria were IFA positive (Table).

Circumsporozoite antibody response of patients with acute falciparum malaria

The CS antibody response of the patients with acute malaria is shown in Fig. 1, A. Sixty-three of the

Table. Circumsporozoite protein and indirect fluorescent antibody response of schoolchildren in study area based on clinical diagnosis

\begin{tabular}{|c|c|c|}
\hline Antibody response & $\begin{array}{l}\text { Children with } \\
\text { recent malaria } \\
\qquad(n=42)\end{array}$ & $\begin{array}{l}\text { Children with } \\
\text { no history of } \\
\text { recent malaria } \\
(n=192)\end{array}$ \\
\hline $\begin{array}{l}\left(\text { NANP }_{40} \text { ELISA }^{a}\right. \\
\geqslant 0.3 \\
0.2-0.3 \\
\leqslant 0.2\end{array}$ & $\begin{array}{c}6(14 \%) \\
3(7 \%) \\
33(79 \%)\end{array}$ & $\begin{array}{c}11(6 \%) \\
4(2 \%) \\
177(92 \%)\end{array}$ \\
\hline $\begin{array}{l}\text { IFAT }^{\mathbf{b}} \\
\text { Positive } \\
\text { Negative }\end{array}$ & $\begin{array}{l}13(31 \%) \\
29(69 \%)\end{array}$ & $\begin{array}{c}2(1 \%) \\
190(99 \%)\end{array}$ \\
\hline
\end{tabular}

a Response (difference in optical density) to (NANP) enzyme-linked immunosorbent assay.

${ }^{b}$ Response to indirect fluorescent antibody test using blood-stage antigen.

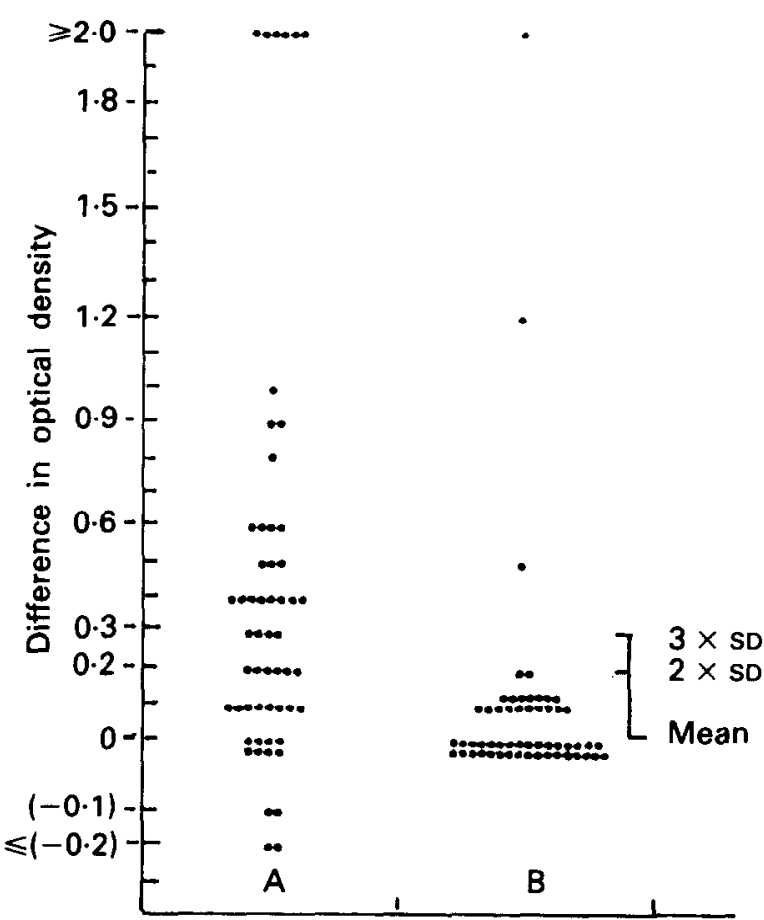

Fig. 2. The (NANP) 40 enzyme-linked immunosorbent assay results of the acute (A) and one year follow-up (B) sera of 55 patients with falciparum malaria. The mean plus 2 and 3 standard deviations of the control group (C in Fig. 1) are shown.
$101(62 \%)$ showed an OD difference $\geqslant 0.2$, and 59 $(57 \%)$ showed an OD difference $\geqslant 0.3$. The remainder did not appear to have mounted an antibody response to the (NANP) 40 antigen.

The antibody OD difference values for the 55 patients retested one year after their initial infection, together with the data on the respective 'acute' sera, are shown in Fig. 2; all but 5 of them $(91 \%)$ had lost the CS antibody. These 5 patients gave no history of malaria, febrile episodes or travel to malarious areas during the intervening year. Three of these patients appeared to retain high levels of CS antibody (OD difference $\geqslant 0 \cdot 3$ ).

Optical density difference and number of recrudescences

The CS antibody OD difference values were similar in those patients experiencing 2, 3, or more recrudescences. The values obtained were: patients with 2 or fewer recrudescences $(n=17)$, mean $=0.41$, $S \mathrm{D}=0.43 ; 3$ recrudescences $(n=21)$, $\mathrm{m}$ e a $\mathrm{n}=0.33$, $\mathrm{SD}=0.37 ; 4$ or more recrudescences $(n=32)$, mean $=0.41, \mathrm{SD}=0.79$. The median values for the three groups were $0.28,0.26$ and 0.2 respectively.

Indirect fluorescence assay response to asexual stage antigens of $\mathrm{P}$. falciparum

Of the 101 sera tested for antibodies against asexual stages, $92(91 \%)$ were positive at a screening dilution

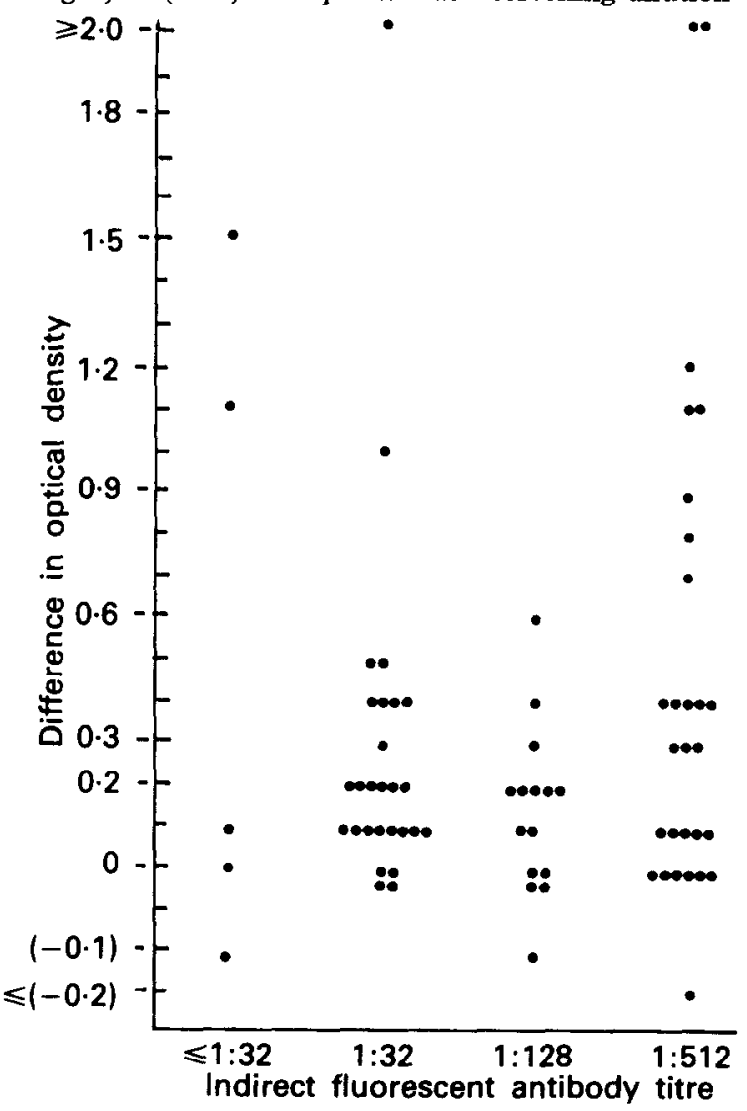

Fig. 3. The relationship between (NANP) 40 enzyme-linked immunosorbent assay results and the indirect fluorescent asexual stage antibody response in 75 patients with acute falciparum malaria. 
of 1 in 32 . With the 75 specimens in which adequate serum was available, the IFA antibody was titrated at dilutions of 1 in 32,1 in 128, and 1 in 512. There appeared to be no correlation of the IFA titres with the corresponding CS OD differences (Fig. 3).

\section{Discussion}

The ELISA for CS antibodies using the synthetic peptide (NANP) 40 antigen has been earlier shown to give results comparable to that using whole sporozoites (DEL GIUDICE $e t$ al., 1987b). The present study reports the CS antibody response in a first exposure to falciparum malaria; the only published report of comparable data was that by DEL GIUDICE el al. (1987b) on Caucasians returning from Africa with acute $P$. falciparum malaria.

In the present study, $49-62 \%$ of the individuals had detectable levels of anti (NANP) 40 antibodies after their initial exposure to $P$. falciparum. These results are comparable to the $48 \%$ antibody prevalence in 51 Caucasian travellers with falciparum malaria reported by DEL GruDICE et al. (1987b). Both studies indicated that an antibody response to the NANP epitope of the CS antigen is not universal, following a single malarial infection. WEBSTER et al. (1987) reported that CS antibody titres (to the R32tet32 recombinant antigen) declined rapidly after the onset of illness, with an apparent half-life for antibody of $27 \mathrm{~d}$. The ELISA OD at day 67 appeared to be related to the peak OD value obtained during the acute illness. In the present study, 3 sera of the 55 patients retested after one year had significantly high OD difference values (Fig. 2). These patients did not give a history of malaria or travel to malarious areas in the intervening year. These sera were among those that gave maximal initial (acute serum) ELISA positivity, which agrees with the observation by WEBSTER et al. (1987). DRUILHE $e t$ al. (1986), using the IFA, also showed that antisporozoite antibodies could persist in the absence of re-exposure. In the present study, most patients had repeated recrudescences of malaria. The clinical and epidemiological evidence points to these being recrudescences rather than reinfections. There was clinical evidence of partial chloroquine/amodiaquine resistance of the epidemic strain. Of 77 patients treated with a standard drug regimen of amodiaquine (1400 mg base over $72 \mathrm{~h}), 62(81 \%)$ had recrudescent illness within $28 \mathrm{~d}$; none of 71 patients treated with sulfadoxine/pyrimethamine (Fansidar $\left.{ }^{\circledR}\right)$ had a further recrudescence. WEBSTER et al. (1987) suggested that the CS antibody response was unaffected by recrudescences of malaria, but showed a boost following reinfection. In the present study, the OD difference values of patients who had 2,3 , or more recrudescences of illness did not show a significant difference, supporting the contention of WEBSTER et al. (1987) that recrudescences do not effect the CS antibody titre.

Of the 234 schoolchildren examined from the area, $42(18 \%)$ were assessed to have had clinical malaria. In this group the IFA, as expected, gave a higher positivity rate $(31 \%)$ than did the CS ELISA $(21 \%)$. The correspondence between the tests was poor. Four of the children (one showed only gametocytaemia), although asymptomatic at examination, showed persistence of asexual parasitaemia, evidence supportive of the partial drug resistance of the infecting parasite strain. A high percentage (8\%) of schoolchildren in the area of the outbreak, with no evidence suggestive of clinical malaria, were positive for $\mathrm{CS}$ antibodies, while only $1 \%$ were positive for blood-stage antibodies. In view of the fact that they had not taken chemoprophylaxis, this could be used as an estimate of exposure to infective bites in the absence of clinical disease. Of the children from the non-malarious area, $2-4 \%$ had antibodies to (NANP) 40 . Although their history suggested that they had never been exposed to malaria, in a tropical country it is not possible completely to rule out contact with the parasite. However, the possibility that some positive results with the CS ELISA may have been false positives, or may have been due to cross-reacting antibodies, needs to be considered. Overall, the results of the study confirm the earlier observations that the antisporozoite antibodies are of short duration, unrelated to recrudescence, and independent of the anti-bloodstage antibodies. The (NANP) ${ }_{40}$ ELISA shows promise of being a potentially valuable sero-epidemiological tool in situations with seasonal transmission, where trends are more important than individual infections. Furthermore, it is useful in situations of low drug resistance and repeated recrudescences, where the antibody response against blood-stages is of limited value in sero-epidemiology.

\section{Acknowledgements}

We are grateful to Ms C. S. Ariyaratne and Ms R. L. A. R. Ranaweera for their exceilent technical assistance. Dr J. Seneviratne was associated with the Waratenne field study. We are grateful to Dr Chev Kidson, Director, Queensland Institute of Medical Research, for making available the antigen slides for the IFA assays.

The field work was financially supported by the US Academy of Sciences through a grant from USAID. Part of this work was supported by the UNDP/World Bank/WHO Special Programme for Research and Training in Tropical Diseases.

\section{References}

Cambell, G. H., Brandling-Bennet, A. D., Roberts, J. M., Collins, F. H., Kaseje, D. C. O., Barber, A. M. \& Turner, A. (1987). Detection of antibodies in human sera to the repeating epitope of the circumsporozoite protein of Plasmodium falciparum using the synthetic peptide $(\mathrm{NANP})_{3}$ in an enzyme-linked immunosorbent assay (ELISA). American Journal of Tropical Medicine and Hygiene, 37, 17-21.

Dame, J. B., Williams, J. L., McCutchan, T. F., Weber, J. L., Wirtz, R. A., Hockmeyer, W. T., Maloy, W. L., Heynes, J. D., Schneider, I., Roberts, D., Sanders, G. S., Reddy, E. P., Diggs, C. L. \& Miller, L. H. (1984). Structure of the gene encoding the immunodominant surface antigen on the sporozoite of the human malaria parasite Plasmodium falciparum. Science, 225, 593-599.

Del Giudice, G., Engers, H. D., Tougne, C., Biro, S. S., Weisse, N., Verdini, A. S., Pessi, A., Degremont, A A., Freyvogel, T. A., Lambert, P. H. \& Tanner, M. (1987a). Antibodies to the repetitive epitope of Plasmodium falciparum circumsporozoite protein in a rural Tanzanian community: a longitudinal study of 132 children. American Journal of Tropical Medicine and Hygiene, 36, 203-212.

Del Giudice, G., Verdini, A. S., Pinori, M., Pessi, A., Verhave, J. P., Tougne, C., Ivanoff, B., Lambert, J. P. $\&$ Engers, H. D. (1987b). Detection of human antibodies against Plasmodium falciparum sporozoites using synthetic peptides. Foumal of Clinical Microbiology, 25, 91-96.

Druilhe, P., Pradier, O., Merc, J. P., Miltgen, F., Mazier, D. \& Parent, G. (1986). Levels of antibodies to 
Plasmodium falciparum sporozoite surface antigens reflect malaria transmission-rates and are persistent in the absence of reinfection. Infection and Immunity, 53, 393-397.

Enea, V., Ellis, J., Zavala, F., Arnot, D. E., Asavanich, A. Masuda, A., Quakyi, I. \& Nussenzweig, R. S. (1984). DNA cloning of Plasmodium falciparum circumsporozoite gene: amino acid sequence of repetitive epitope. Science, 225, 628-630.

Hoffman, L. S., Wistar, R., Jr, Ballou, W. R., Hollingdale, M. R., Wirtz, R. A., Schneider, I., Merwoto, H. A. M. S. \& Hockmeyer, W. T. (1986). Immunity to malaria and naturally acquired antibodies to the circumsporozoite protein of Plasmodium falciparum. New England Journal of Medicine, 315, 601-606.

Nardin, E. H., Nussenzweig, R. S., McGregor, I. A. \& Bryan, J. H. (1979). Antibodies to sporozoites; their frequent occurrence in individuals living in an area of hyperendemic malaria. Science, 206, 597-599.

Nussenzweig, V. \& Nussenzweig, R. S. (1985). Circumsporozoite proteins of malaria parasites. Cell, 42, 401403.

Tapchaisri, P., Chomcharn, Y., Poonthong, C., Asavanich, A., Limsuwan, S., Maleevan, O., Tharavanij, S. \&
Harinasuta, T. (1983). Anti-sporozoite antibodies induced by natural infections. American fournal of Tropical Medicine and Hygiene, 32, 1203-1208.

Vandenberg, J. P., Nussenzweig, R. S. \& Most, H. (1969). Protective immunity produced by the injection of $\mathrm{X}$-irradiated sporozoites of Plasmodium berghei. V. In vitro effects of immune serum on sporozoites. Military Medicine, 134, Supplement, 1183-1190.

Webster, H. K., Boudreau, E. F., Pang, L. W., Permpanich, B., Sookto, P. \& Wirtz, R. A. (1987). Development of immunity in natural Plasmodium falciparum malaria: antibodies to the falciparum sporozoite vaccine 1 antigen (R32tet32). Foumal of Clinical Microbiology, 25, 1002-1008.

Wijesundera, M. de S. (1988). Malaria outbreak in new foci in Sri Lanka. Parasitology Today, 4, 147-150.

Zavala, F., Tam, J. P. \& Masuda, A. (1986). Synthetic peptides as antigens for the detection of humoral immunity to Plasmodium falciparum sporozoites. Joumal of Immunological Methods, 93, 55-61.

Received 13 March 1989; revised 17 fuly 1989; accepted for publication 19 fuly 1989

\section{ROYAL SOCIETY OF TROPICAL MEDICINE AND HYGIENE}

The Transactions of the Royal Society of Tropical Medicine and Hygiene is issued bi-monthly (six parts per year) and publishes not only papers presented at Society meetings and symposia but also papers and correspondence submitted from all over the world on every aspect of tropical medicine and health. Supplements on specialist topics are published from time to time.

The Transactions is available to Libraries and non-Fellows at an annual subscription of £75. It is dispatched by Accelerated Surface Post at no extra charge.

The annual subscription to Fellows is $£ 35$. Applications for Fellowship must be made on the correct form, obtainable from the address below.

Further information from:

The Honorary Secretaries,

Royal Society of Tropical Medicine and Hygiene,

Manson House,

26 Portland Place,

London WIN 4EY 